\title{
Individual characteristics, area social participation, and primary non-concordance with medication: a multilevel analysis Kristina Johnell*1, Martin Lindström² ${ }^{2}$, Jan Sundquist ${ }^{1}$, Charli Eriksson ${ }^{3}$ and Juan Merlo ${ }^{2}$
}

Address: ${ }^{1}$ Centre for Family Medicine, Karolinska Institutet, Stockholm, Sweden, ${ }^{2}$ Community Medicine (Dept Clin Sci), Malmö University Hospital, Faculty of Medicine, Lund University, Sweden and ${ }^{3}$ Department of Community Medicine and Public Health, Regional Medical Centre, Örebro, Sweden

Email: Kristina Johnell* - Kristina.Johnell@ki.se; Martin Lindström - Martin.Lindstrom@med.lu.se; Jan Sundquist - Jan.Sundquist@ki.se; Charli Eriksson - Charli.Eriksson@hi.oru.se; Juan Merlo - Juan.Merlo@med.lu.se

* Corresponding author

Published: 02 March 2006

BMC Public Health2006, 6:52 doi:10.1 I86/1471-2458-6-52
Received: 24 October 2005

Accepted: 02 March 2006

This article is available from: http://www.biomedcentral.com/I47I-2458/6/52

(c) 2006Johnell et al; licensee BioMed Central Ltd.

This is an Open Access article distributed under the terms of the Creative Commons Attribution License (http://creativecommons.org/licenses/by/2.0), which permits unrestricted use, distribution, and reproduction in any medium, provided the original work is properly cited.

\begin{abstract}
Background: Non-concordance with medication remains a major public health problem that imposes a considerable financial burden on the health care system, and there is still a need for studies on correlates of non-concordance. Our first aim is to analyse whether any of the individual characteristics age, educational level, financial strain, self-rated health, social participation, and trust in the health care system are associated with primary non-concordance with medication. Our second aim is to investigate whether people living in the same area have similar probability of primary non-concordance with medication, that relates to area social participation.
\end{abstract}

Methods: We analysed cross sectional data from 9070 women and 6795 men aged 18 to 79 years, living in 78 areas in central Sweden, who participated in the Life \& Health year 2000 survey, with multilevel logistic regression (individuals at the first level and areas at the second level).

Results: Younger age, financial strain, low self-rated health, and low trust in the health care system were associated with primary non-concordance with medication. However, area social participation was not related to primary non-concordance, and the variation in primary nonconcordance between the areas was small.

Conclusion: Our results indicate that people in central Sweden with younger age, financial difficulties, low self-rated health, and low trust in the health care system may have a higher probability of primary non-concordance with medication. However, the area of residence - as defined by administrative boundaries - seems to play a minor role for primary non-concordance.

\section{Background}

Patients' concordance with medication is a prerequisite for effective drug therapy. Non-concordance is a major public health problem that imposes a considerable financial burden on the health care system $[1,2]$. Despite the comprehensive research on concordance during the last decades [3], non-concordance remains a concern in health care, and there is still a need for studies on correlates of non-concordance because the complex phenomenon of non-concordance is far from understood. It has 
been suggested that the social context in which non-concordance occurs should not be ignored $[1,2,4]$, and we have tried to incorporate this aspect in this study.

The term concordance implies agreement, trust, and harmony between patient and doctor regarding treatment, and acknowledges the patient as a decision maker, and a cornerstone is professional empathy $[2,5]$. The members of a working party of the Royal Pharmaceutical Society of Great Britain introduced the term concordance, which recognizes a patient's own choice to concord with treatment [2].

Patient non-concordance with medication may be divided into primary non-concordance, where the patient does not redeem the prescription, and secondary nonconcordance, where the patient does not take the medication as prescribed $[2,6]$. Most studies have focused on secondary non-concordance [7-9]. Nevertheless, it is crucial to determine whether patients actually redeem their prescriptions from the pharmacy, because this is the first step in the complex phenomenon of concordance [9]. Studies on primary non-concordance have reported non-redemption rates between $2 \%$ and $33 \%$ [6-16]. However, these studies vary greatly regarding assessment of primary nonconcordance, participants, and setting.

Individual characteristics, such as age, educational level, self-rated health, and social support have been discussed as correlates of concordance, however, the results are inconsistent $[1-3,17,18]$. On the other hand, the influence of area factors, related to one's area of residence, have been scarcely investigated in relation to concordance. Yet, over and above individual characteristics, patients' concordance with medication might be related to the social context in which they live $[1,4]$. In a previous study, we observed that the association between social participation and concordance with antihypertensives varied among municipalities in Scania, Sweden (i.e., cross-level interaction) [19], which suggests that the area of residence may influence the mechanisms behind the concordance behaviour.

Individual social participation describes how actively a person takes part in activities, groups, and associations, and social participation has been associated with healthrelated behaviours, such as smoking cessation [20] and physical activity [21]. Further, social participation is important for understanding the influence of social factors on health [22], and can be viewed as a feature of individual social networks [23]. Social participation and social networks have been suggested to influence health behaviours, such as concordance with medication, possibly through information exchange and establishment of health-related group norms $[23,24]$. In our previous study in Scania, our results suggested an association between low social participation and low concordance with antihypertensives [19], and, therefore, we wanted to further investigate whether social participation, both at the individual and at the area level, was associated with general primary non-concordance with medication, in a different setting.

The area level of social participation has been considered as a structural component within the concept of social capital $[24,25]$, which describes social structures and social relationships in society [24]. Living in an area with low social capital might decrease the individual probability of concordance with medication through mechanisms like poorer social networks [17], shared norms around health-related behaviour, transmission of health information, health care system factors [26], and social control over deviant health-related behaviour [23,27]. Previous studies have found associations between living in a disadvantaged area [28], with low social capital $[29,30]$, and use of medication. We were therefore interested in investigating whether social capital, as measured by the area level of social participation, might be related to primary non-concordance with medication.

Because of our contextual approach in this study, we used multilevel analysis, which handles information on both people and context simultaneously within the same model [31], and we investigated measures of variation as well as traditional measures of association [32,33].

The first aim of this study is to analyse whether any of the individual characteristics age, educational level, financial strain, self-rated health, social participation, and trust in the health care system are associated with primary nonconcordance with medication. The second aim is to investigate whether people living in the same area have similar probability of primary non-concordance with medication, that relates to area social participation.

\section{Methods Study sample}

We used data from the Life \& Health year 2000 survey [34], a postal questionnaire administered by Statistics Sweden. A random sample of 70044 people, aged 18-79 years from 58 municipalities in six regions in central Sweden (Södermanland, Uppsala, Värmland, Västmanland, and Örebro county, and south Dalarna), had the opportunity to participate in the survey and 46636 (67\%) returned the questionnaire. The purpose of the survey was to generate self-reported information about people's life and health in the area and was complemented with register data on age, sex, place of residence, and educational level. Of the 46636 participants, we included those who reported having visited an emergency department, a phy- 
sician at a hospital department, a primary care physician, or been admitted to a hospital during the last 3 months ( $\mathrm{n}$ $=20362$ ), and with complete information on all the variables studied ( $\mathrm{n}=9070$ women and 6795 men).

The areas in this study correspond to municipalities, except for Uppsala, Västerås, and Örebro (the three largest cities in the sample region), which were divided into ten, eight, and five smaller urban areas, respectively. In total, there were 78 areas.

\section{Outcome variable}

Primary non-concordance with medication (dichotomous) was assessed by the question "During the last 3 months, have you received a prescription for medicine, but not redeemed the medicine?"

\section{Explanatory variables}

The correlates of non-concordance were selected by reviewing the literature and grouped into a) social and economic factors and b) Health care system and area factors, as suggested by the World Health Organization (WHO) [26].

\section{Social and economic factors}

Age was categorized into four groups: 18-34 years, 35-49 years, 50-64 years, and 65-79 years (used as reference category).

Educational level was dichotomised into $\geq 9$ years of education (i.e., compulsory school) (low educational level) and $>9$ years [35].

Financial strain was assessed by a negative answer to the question, "Would you manage to raise 18000 SEK (about 1900 Euro) in 1 week?" (dichotomous).

Self-rated health was assessed by the question "How do you rate your general health status?" and dichotomised into "neither good nor bad/bad/very bad health" (low self-rated health) and "good/very good health" [36].

Individual social participation was defined by active membership [37] in a labour union, political party, council/ board, community centre, sports association, cultural association/choir/orchestra/theatre group etc., religious association/community, or other association. Participants without any active membership in any of these associations were considered to have low social participation (dichotomous).

\section{Health care system and area factors}

Trust in the health care system was assessed by the question "How much do you trust the following institutions in society?" and for "The health care system" indicating "not particularly high trust/no trust/have no opinion" (low trust in the health care system) and "very high trust/fairly high trust" (dichotomous)

Area low social participation was based on a larger sample from the Life \& Health year 2000 survey (20 715 women and 18190 men), and was estimated by the proportion of participants in the area who were classified as having low social participation $[29,30,37]$. Area low social participation was then divided into tertiles.

\section{Statistical analysis}

We used multilevel logistic regression analysis [38] with individuals at the first level and areas at the second level. Men and women were analysed separately, in order to see whether the associations between the explanatory variables and the outcome were different for men and women.

In Model i (empty model), we did not include any explanatory variables. In Model ii, we included only the individual variables, i.e., age, education, financial strain, selfrated health, social participation, and trust in the health care system. In Model iii, we added area low social participation, because we wanted to investigate the influence of area low social participation on primary non-concordance with medication, after adjustment for the individual (compositional) variables.

\section{Fixed effects (measures of association)}

The results are shown as odds ratios (ORs) with $95 \%$ confidence intervals (CIs).

\section{Random effects (measures of variation)}

We examined whether the area of residence had a general contextual effect on individual primary non-concordance. In other words, we wanted to establish whether individuals living in the same area shared a similar probability of primary non-concordance, after adjusting for the individual characteristics studied. This hypothesized contextual phenomenon [33] was measured by the intraclass correlation (ICC) and the median odds ratio (MOR). We also applied the $80 \%$ interval odds ratio (80\%IOR), which integrates random effects (i.e., area variance) in the measurement of fixed effects (i.e., the area variable) [38,39]. We refer elsewhere[38,39] for a more detailed explanation of the ICC, MOR and IOR. However, in short, the ICC is the proportion of the total variance (i.e., the variance at the area level plus the variance at the individual level) that is at the area level. In the multilevel logistic regression, there are different ways to calculate the ICC [40]; however, we chose the threshold model, as described by Snijders \& Bosker [41]. An advantageous alternative to the ICC in the multilevel logistic regression is the MOR, which measures area variance in the odds ratio scale. If the MOR is equal to 1 (no area level variance), there is no difference 
Table I: Characteristics of the 9070 women and 6795 men from the Life \& Health year 2000 survey, Sweden. Unless otherwise indicated, values are given in percent.

\begin{tabular}{lll}
\hline & Women & Men \\
\hline Mean age & 49 years & 53 years \\
\hline Primary non-concordance with medication & 7.6 & 6.5 \\
Low educational level & 30.6 & 33.9 \\
Financial strain & 33.7 & 24.2 \\
Low self-rated health & 45.9 & 44.2 \\
Low social participation & 54.9 & 47.5 \\
Low trust in the health care system & 26.2 & 25.1 \\
Active membership in associations (social participation) & & \\
Labour union & 4.1 & 4.7 \\
Political party & 2.2 & 3.2 \\
Council/board & 2.9 & 2.7 \\
Community centre & 3.0 & 4.0 \\
Sports association & 8.9 & 15.5 \\
Cultural association/choir/orchestra/theatre group, etc. & 7.9 & 7.7 \\
Religious association/community & 6.1 & 4.5 \\
Other association & 22.7 & 26.5 \\
\hline
\end{tabular}

between the areas regarding primary non-concordance. Conversely, the higher the MOR, the more important the contextual effects for understanding the individual probability of primary non-concordance.

The IOR considers the magnitude of the difference between the areas regarding primary non-concordance when interpreting the influence of area variables. It has been suggested to report the IOR as an $80 \%$ interval, and also, the IOR is not an ordinary confidence interval. If the IOR contains 1 , the remaining unexplained difference between the areas regarding primary non-concordance is large compared with the effect of the area variable. However, if the IOR does not contain 1, the effect of the area variable is large compared with the unexplained difference between the areas.

The MLwiN software, version 2.0 [42], was used for the analyses. Parameters were estimated using the Markov Chain Monte Carlo (MCMC) procedure. We used the default settings in MLwiN, i.e., chains of length 5000 after a burn-in of 500. The Deviance Information Criterion (DIC) was used as a measure of how well our different models fitted the data. A lower value on DIC indicates a better fit of the model $[43,44]$.

\section{Results}

The prevalence of primary non-concordance with medication was $7.6 \%$ (range across the 78 areas: $2 \%-14 \%$ ) for women and $6.5 \%$ (range across the 78 areas: $0 \%-15 \%$ ) for men in the study sample. Financial strain and low social participation were more frequent among women than among men (table 1).
Further, table 1 shows the distribution of active membership in associations (social participation) in the study sample. Active membership in sports associations was fairly frequent (i.e., in $8.9 \%$ of women and $15.5 \%$ of men). However, a large proportion of the participants were members of "other", unknown, associations (i.e., $22.7 \%$ of women and $26.5 \%$ of men).

The median (first to third quartile) number of participants in the areas was 115 (102-126) women and 86 (72-94) men. Area low social participation ranged from $45 \%$ to $63 \%$.

\section{Fixed effects}

\section{Social and economic factors}

In Model ii, the association between age and primary nonconcordance with medication was inversed (table 2 and 3 ). Moreover, we did not find any association between educational level and primary non-concordance, but we found an association between financial strain and primary non-concordance $\left(\mathrm{OR}_{\text {women }}=1.87(95 \%\right.$ CI $1.58-$ $2.22)$ and $\left.\mathrm{OR}_{\mathrm{men}}=2.24(95 \% \mathrm{CI} 1.82-2.75)\right)$. Also low self-rated health $\left(\mathrm{OR}_{\text {women }}=1.38(95 \% \mathrm{CI} 1.16-1.63)\right.$ and $\mathrm{OR}_{\mathrm{men}}=1.58(95 \%$ CI 1.28-1.95)) was associated with primary non-concordance. The lower DIC value in Model ii indicated a better fit than in Model i (the empty model).

Health care system and area factors

In Model ii, low trust in the health care system $\left(\left(\mathrm{OR}_{\text {women }}\right.\right.$ $=1.33(95 \% \mathrm{CI} 1.12-1.58)$ and $\mathrm{OR}_{\mathrm{men}}=1.37(95 \% \mathrm{CI}$ 1.11-1.69)) was related to primary non-concordance.

In Model iii, area low social participation was not associated with primary non-concordance. Furthermore, the 
Table 2: Area variance and odds ratios (ORs) with $95 \%$ confidence intervals (95\% Cls) for individual variables and area low social participation regarding primary non-concordance with medication among 9070 women from the Life \& Health year 2000 survey, Sweden.

\begin{tabular}{|c|c|c|c|c|c|c|}
\hline & Model i (empty model) & \multicolumn{2}{|c|}{ Model ii } & \multicolumn{3}{|c|}{ Model iii } \\
\hline & $95 \% \mathrm{Cl}$ & OR & $95 \% \mathrm{Cl}$ & OR & $95 \% \mathrm{Cl}$ & $80 \%$ IOR \\
\hline \multicolumn{7}{|l|}{ Fixed effects } \\
\hline \multicolumn{7}{|l|}{ Age } \\
\hline $65-79$ years & & Ref & & Ref & & \\
\hline $50-64$ years & & 1.58 & $(1.16-2.15)$ & 1.55 & $(1.18-2.03)$ & \\
\hline $35-49$ years & & 2.49 & $(1.82-3.43)$ & 2.46 & $(1.88-3.22)$ & \\
\hline $18-34$ years & & 3.22 & $(2.36-4.39)$ & 3.17 & $(2.4 I-4.17)$ & \\
\hline Low educational level (yes vs. no) & & 0.85 & $(0.71-1.03)$ & 0.85 & $(0.71-1.03)$ & \\
\hline Financial strain (yes vs. no) & & 1.87 & $(1.58-2.22)$ & 1.85 & $(1.57-2.18)$ & \\
\hline Low self-rated health (yes vs. no) & & 1.38 & $(1.16-1.63)$ & 1.37 & $(1.16-1.62)$ & \\
\hline Low social participation (yes vs. no) & & 0.87 & $(0.74-1.02)$ & 0.86 & $(0.73-1.02)$ & \\
\hline Low trust in the health care system (yes vs. no) & & 1.33 & $(1.12-1.58)$ & 1.34 & $(1.13-1.58)$ & \\
\hline \multicolumn{7}{|l|}{ Area low social participation in tertiles } \\
\hline I 190 & & & & Ref & & \\
\hline 2 & & & & 1.22 & $(0.99-1.50)$ & $0.98-|.5|$ \\
\hline 3 & & & & 1.10 & $(0.89-1.35)$ & $0.88-1.36$ \\
\hline \multicolumn{7}{|l|}{ Random effects } \\
\hline Area intercept variance (SE) & $0.014(0.015)$ & & $12(0.013)$ & & $0.014(0.01$ & \\
\hline Median odds ratio & 1.12 & & 1.11 & & 1.12 & \\
\hline Intraclass correlation & $0.4 \%$ & & $0.4 \%$ & & $0.4 \%$ & \\
\hline Deviance information criterion & 4888 & & 4686 & & 4686 & \\
\hline
\end{tabular}

DIC value in Model iii showed that the addition of area low social participation did not improve the fit.

\section{Random effects}

The area intercept variance in the different analyses was small, ranging from 0.012 to 0.036 (table 2 and 3). Accordingly, the MOR and the ICC were also small, the MOR ranging from 1.11 to 1.20 and the ICC ranging from $0.4 \%$ to $1.1 \%$.

Moreover, the $80 \%$ IORs included 1 for area low social participation, and thereby confirmed the low importance, in this study, of this area characteristic for primary nonconcordance.

We did not find any interaction between individual and area social participation.

\section{Discussion}

\section{Main findings}

Our results indicate that the individual characteristics younger age, financial strain, low self-rated health, and low trust in the health care system are associated with primary non-concordance with medication. Our finding that younger age is associated with higher primary non-concordance is in line with previous studies on primary nonconcordance $[10,13,15]$.
Research on education and concordance has been inconclusive $[1,18]$, and we did not either find an association between educational level and primary non-concordance. However, there was a relation between financial strain and primary non-concordance. All residents in Sweden who have spent 1800 SEK (about 190 Euro) on medication within the preceding 12 months are entitled to free prescribed medicines through the social security system [45]. Despite this subsidy, participants in this study who experienced financial strain seemed to have difficulties redeeming their medication. It has previously been reported that financial barriers contribute to non-concordance $[3,7,12,13,45-47]$, and that people who restrict their use of medication because of cost have worse health outcomes [48].

Also, we observed an association between low self-rated health and primary non-concordance. However, previous studies on self-rated health and concordance have given different results [18].

Furthermore, we found a relation between low trust in the health care system and primary non-concordance. There is an ongoing discussion about the lack of people's trust in health care system and health care professionals [49-55]. It is known that trust and the quality of the doctor-patient relationship are important for concordance with medica- 
Table 3: Area variance and odds ratios (ORs) with $95 \%$ confidence intervals (95\% Cls) for individual variables and area low social participation regarding primary non-concordance with medication among 6795 men from the Life \& Health year 2000 survey, Sweden.

\begin{tabular}{|c|c|c|c|c|c|c|}
\hline & Model i (empty model) & \multicolumn{2}{|c|}{ Model ii } & \multicolumn{3}{|c|}{ Model iii } \\
\hline & $95 \% \mathrm{Cl}$ & OR & $95 \% \mathrm{Cl}$ & OR & $95 \% \mathrm{Cl}$ & $80 \%$ IOR \\
\hline \multicolumn{7}{|l|}{ Fixed effects } \\
\hline \multicolumn{7}{|l|}{ Age } \\
\hline $65-79$ years & & Ref & & Ref & & \\
\hline $50-64$ years & & 1.57 & $(1.18-2.09)$ & 1.57 & $(1.17-2.09)$ & \\
\hline $35-49$ years & & 2.23 & $(1.64-3.04)$ & 2.19 & $(1.61-2.98)$ & \\
\hline 18-34 years & & 2.29 & $(1.67-3.13)$ & 2.26 & $(1.62-3.16)$ & \\
\hline Low educational level (yes vs. no) & & 0.87 & $(0.69-1.10)$ & 0.87 & $(0.70-1.09)$ & \\
\hline Financial strain (yes vs. no) & & 2.24 & $(1.82-2.75)$ & 2.25 & $(1.84-2.76)$ & \\
\hline Low self-rated health (yes vs. no) & & 1.58 & $(1.28-1.95)$ & 1.58 & $(1.29-1.93)$ & \\
\hline Low social participation (yes vs. no) & & 0.85 & $(0.69-1.03)$ & 0.85 & $(0.69-1.03)$ & \\
\hline Low trust in the health care system (yes vs. no) & & 1.37 & $(1.11-1.69)$ & 1.38 & $(1.11-1.72)$ & \\
\hline \multicolumn{7}{|l|}{ Area low social participation in tertiles } \\
\hline 1 & & & & Ref & & \\
\hline 2 & & & & 1.07 & $(0.80-1.43)$ & $0.76-|.5|$ \\
\hline 3 & & & & 0.83 & $(0.62-1.11)$ & $0.59-1.17$ \\
\hline \multicolumn{7}{|l|}{ Random effects } \\
\hline Area intercept variance (SE) & $0.034(0.033)$ & & $34(0.033)$ & & $0.036(0.0$ & \\
\hline Median odds ratio & 1.19 & & 1.19 & & 1.20 & \\
\hline Intraclass correlation & $1.0 \%$ & & $1.0 \%$ & & $1.1 \%$ & \\
\hline Deviance information criterion & 3288 & & 3148 & & 3148 & \\
\hline
\end{tabular}

tion $[2,51,56-58]$. Possible ways to enhance patient trust may be continuity of care from a regular doctor [59] and provision of patient centred care where the patient gets enough attention [60]. Future studies of why some people have low trust in the health care system and how this trust can be enhanced are needed.

Further, area social participation was not associated with primary non-concordance with medication. The low importance of the area is further supported by the low area variances and, hence, the low MORs in the analyses, which indicate that the area of residence, as measured in this study, does not seem to be important for primary non-concordance. Nevertheless, one alternative explanation could be that the choice of areas in this study as municipalities and the way we measured the aggregated variable area social participation did not capture the context important for primary non-concordance. We expected area social participation, a main aspect of social capital, to be related to primary non-concordance with medication because of mechanisms like poorer social networks, shared norms around health-related behaviour, transmission of health information, and social control over deviant health-related behaviour $[23,27]$. Indeed, related research suggests that social capital and deprivation plays a role in use of medication $[28,30]$, how health care is per- ceived by citizens [61] and people's trust in their physicians may be influenced by contextual variables [62].

\section{Limitations}

The study sample consisted of those who had visited an emergency department, a physician at a hospital department, a primary care physician, or been admitted to a hospital. With this definition of population at risk we tried to include individuals that had had some contact with the health care system and therefore could have received a prescription. However, this definition may not adequately capture people "at risk" of not redeeming a prescription for medicine.

We used self-reported concordance, which has been found to correlate with other measures of concordance and with clinical measures of disease activity [63-65]. Further, self-report offers a convenient and non-invasive estimate of concordance behaviour. However, the procedure of measuring concordance is controversial. Self-report can be subject to self-presentational and recall biases. People may overestimate their concordance and their memory may be inaccurate [66].

The WHO has suggested five sets of correlates of non-concordance: social and economic factors, health care system 
factors, condition-related factors, therapy-related factors, and patient-related factors [26]. We have only addressed two of these five sets of correlates: social and economic factors and health care system and area factors. Future studies of non-concordance may try to also capture the less often studied condition-related factors, such as severity of symptoms, and therapy-related factors, such as the complexity of the medical regimen.

People living in deprived areas and with low socio-economic status, low self-rated health, and primary non-concordance with medication may have been less inclined to respond to the Life \& Health year 2000 survey. Analyses of the excluded responders with incomplete information on the variables studied showed that they were, in general, older, and had lower educational level and lower selfrated health, than those included in this study. This possible selection bias could lead to an underestimation of the associations between the explanatory variables in this study and the outcome primary non-concordance with medication.

The cross-sectional design of this study is a weakness, because the direction of causality is impossible to determine. However, the direction of causality from individual characteristics to primary non-concordance seems to be the most plausible.

\section{Conclusion}

Our results indicate that people in central Sweden with younger age, financial difficulties, low self-rated health, and low trust in the health care system may have a higher probability of primary non-concordance with medication. However, the area of residence - as defined by administrative boundaries - seems to play a minor role for primary non-concordance.

Future studies of why some people have low trust in the health care system and how this trust can be enhanced are needed.

\section{Competing interests}

The author(s) declare that they have no competing interests.

\section{Authors' contributions}

$\mathrm{KJ}$ and JM developed the original idea, participated in the design of the study, performed the statistical analyses, and drafted the manuscript. ML and JS participated in the design of the study and revised the manuscript. CE participated in the design of the study, helped to collect the data, and revised the manuscript. All authors read and approved the final manuscript.

\section{Acknowledgements}

This study was financed by the County of Skåne's Pharmacological council and the NEPI Foundation (Juan Merlo), by an ALF-Government Grant, Dnr M:B 19 1003/2004 (Martin Lindström), the Swedish Corporation of Pharmacies' Fund for Research and Studies in Health Economics and Social Pharmacy (Kristina Johnell), the Swedish Council for Working Life and Social Research (Principal investigator Juan Merlo, \# 2003-0580), the Swedish Medical Research Council (Principal investigator Juan Merlo, \# 2004-6155) and National Institutes of Health (ROI HL7I084-0I).

\section{References}

I. Morris LS, Schulz RM: Patient compliance--an overview. J Clin Pharm Ther 1992, 17:283-295.

2. Vermeire E, Hearnshaw H, Van Royen P, Denekens J: Patient adherence to treatment: three decades of research. A comprehensive review. J Clin Pharm Ther 200I, 26:33I-342.

3. DiMatteo MR: Variations in patients' adherence to medical recommendations: a quantitative review of $\mathbf{5 0}$ years of research. Med Care 2004, 42:200-209.

4. Kidd KE, Altman DG: Adherence in social context. Control Clin Trials 2000, 21 : I84S-7S.

5. Bissell P, May CR, Noyce PR: From compliance to concordance: barriers to accomplishing a re-framed model of health care interactions. Soc Sci Med 2004, 58:85I-862.

6. Rashid A: Do patients cash prescriptions? Br Med J (Clin Res Ed) 1982, 284:24-26.

7. Jones I, Britten $\mathrm{N}$ : Why do some patients not cash their prescriptions? Br J Gen Pract 1998, 48:903-905.

8. Saunders CE: Patient compliance in filling prescriptions after discharge from the emergency department. Am J Emerg Med 1987, 5:283-286.

9. Matsui D, Joubert GI, Dykxhoorn S, Rieder MJ: Compliance with prescription filling in the pediatric emergency department. Arch Pediatr Adolesc Med 2000, I 54: $195-198$.

10. Ekedahl A, Mansson N: Unclaimed prescriptions after automated prescription transmittals to pharmacies. Pharm World Sci 2004, 26:26-31.

II. Hagstrom B, Mattsson B, Rost IM, Gunnarsson RK: What happened to the prescriptions? A single, short, standardized telephone call may increase compliance. Fam Pract 2004, 2 I:46-50.

12. Begg D: Do patients cash prescriptions? An audit in one practice. J R Coll Gen Pract 1984, 34:272-274.

13. Beardon PH, McGilchrist MM, McKendrick AD, McDevitt DG, MacDonald TM: Primary non-compliance with prescribed medication in primary care. Bmj 1993, 307:846-848.

14. Christensen DB, Williams B, Goldberg HI, Martin DP, Engelberg R, LoGerfo JP: Assessing compliance to antihypertensive medications using computer-based pharmacy records. Med Care 1997, 35: II64-1170.

15. Bailey JE, Lee MD, Somes GW, Graham RL: Risk factors for antihypertensive medication refill failure by patients under Medicaid managed care. Clin Ther 1996, I 8: I252-1 262.

16. Fincham JE, Wertheimer Al: Using the health belief model to predict initial drug therapy defaulting. Soc Sci Med 1985, 20:10I-105.

17. DiMatteo MR: Social support and patient adherence to medical treatment: a meta-analysis. Health Psychol 2004, 23:207-2I8.

18. Vik SA, Maxwell CJ, Hogan DB: Measurement, correlates, and health outcomes of medication adherence among seniors. Ann Pharmacother 2004, 38:303-3I2.

19. Johnell K, Rastam L, Lithman T, Sundquist J, Merlo J: Low adherence with antihypertensives in actual practice: the association with social participation--a multilevel analysis. BMC Public Health 2005, 5:17.

20. Lindstrom M, Hanson BS, Ostergren PO, Berglund G: Socioeconomic differences in smoking cessation: the role of social participation. Scand J Public Health 2000, 28:200-208.

21. Lindstrom M, Moghaddassi M, Merlo J: Social capital and leisure time physical activity: a population based multilevel analysis in Malmo, Sweden. J Epidemiol Community Health 2003, 57:23-28.

22. Marmot MG: Understanding social inequalities in health. Perspect Biol Med 2003, 46:S9-23.

23. Berkman LF, Glass T, Brissette I, Seeman TE: From social integration to health: Durkheim in the new millennium. Soc Sci Med 2000, 5 I:843-857. 
24. Kawachi I, Berkman LF: Social Cohesion, Social Capital, and Health. In Social Epidemiology Edited by: Berkman LF and Kawachi I. New York, Oxford University Press; 2000: I74-190.

25. Lochner K, Kawachi I, Kennedy BP: Social capital: a guide to its measurement. Health Place 1999, 5:259-270.

26. World Health Organization (WHO). Adherence to longterm therapies: evidence for action (http://www.who.int/ chronic_conditions/adherencereport/en/). 2003.

27. Macintyre S, Ellaway A: Ecological Approaches: Rediscovering the Role of the Physical and Social Environment. In Social Epidemiology Edited by: Berkman LFKI. New York, Oxford University Press; 2000:332-348.

28. Groenewegen PP, Leufkens HG, Spreeuwenberg P, Worm W: Neighbourhood characteristics and use of benzodiazepines in The Netherlands. Soc Sci Med 1999, 48:1701-I71।.

29. Johnell K, Merlo J, Lynch J, Blennow G: Neighbourhood social participation and women's use of anxiolytic-hypnotic drugs: a multilevel analysis. J Epidemiol Community Health 2004, 58:59-64.

30. Merlo J, Lynch JW, Yang M, Lindstrom M, Ostergren PO, Rasmusen NK, Rastam L: Effect of neighborhood social participation on individual use of hormone replacement therapy and antihypertensive medication: a multilevel analysis. Am J Epidemiol 2003, I 57:774-783.

31. Duncan C, Jones K, Moon G: Context, composition and heterogeneity: using multilevel models in health research. Soc Sci Med 1998, 46:97-II7.

32. Merlo J: Multilevel analytical approaches in social epidemiology: measures of health variation compared with traditional measures of association. J Epidemiol Community Health 2003, 57:550-552.

33. Merlo J, Yang M, Chaix B, Lynch J, Rastam L: A brief conceptual tutorial on multilevel analysis in social epidemiology: investigating contextual phenomena in different groups of people. jEpidemiol Community Health 2005, 59:729-736.

34. Berglund K, Eriksson C, Eriksson HG, Feldman I, Lambe M, Molarius A, Nordström E: Conditions of life, habits of life, and health. A report from the survey Life \& health year 2000. Report no 8 (in Swedish). 2003.

35. Statistics Sweden. Swedish nomenclature for education. (http://www.scb.se/templates/Standard_6259I.asp).

36. Eriksson I, Unden AL, Elofsson S: Self-rated health. Comparisons between three different measures. Results from a population study. Int J Epidemiol 200I, 30:326-333.

37. Lochner KA, Kawachi I, Brennan RT, Buka SL: Social capital and neighborhood mortality rates in Chicago. Soc Sci Med 2003, 56: $1797-1805$

38. Larsen K, Merlo J: Appropriate assessment of neighborhood effects on individual health: integrating random and fixed effects in multilevel logistic regression. Am J Epidemiol 2005, | 6 |:8|-88.

39. Larsen K, Petersen JH, Budtz-Jorgensen E, Endahl L: Interpreting parameters in the logistic regression model with random effects. Biometrics 2000, 56:909-9|4.

40. Goldstein H, Browne W, Rasbash J: Partitioning variation in generalised linear multilevel models. Understanding Statistics 2002, I:223-232.

4I. Snijders TAB, Bosker RJ: Multilevel analysis - an introduction to basic and advanced multilevel modeling. Thousand Oaks, California, SAGE Publications; 1999.

42. Rasbash J, Steele F, Browne W, Prosser B: A user's guide to MLwiN. Version 2.0. London, Centre of Multilevel Modelling, Institute of Education, University of London; 2004.

43. Browne W: MCMC estimation in MLwiN. Version 2.0. London, Centre of Multilevel Modelling, Institute of Education, University of London; 2003.

44. Spiegelhalter DJ, Best NG, Carlin BP, van der Linde A: Bayesian measures of model complexity and fit. J R Stat Soc B 2002, 64:583-639.

45. The National Board of Health and Welfare: The reform of medication in 1997 - how did it turn out? (in Swedish). Stockholm, The National Board of Health and Welfare; 2000.

46. Piette JD, Heisler M, Wagner TH: Cost-related medication underuse among chronically ill adults: the treatments people forgo, how often, and who is at risk. Am J Public Health 2004, 94: $1782-1787$
47. Kaplan RC, Bhalodkar NC, Brown EJJ, White J, Brown DL: Race, ethnicity, and sociocultural characteristics predict noncompliance with lipid-lowering medications. Prev Med 2004, 39: | 249- 1255.

48. Heisler M, Langa KM, Eby EL, Fendrick AM, Kabeto MU, Piette JD: The health effects of restricting prescription medication use because of cost. Med Care 2004, 42:626-634.

49. Murphy J, Chang H, Montgomery JE, Rogers WH, Safran DG: The quality of physician-patient relationships. Patients' experiences 1996-1999. J Fam Pract 200I, 50:123-I29.

50. McKinlay JB, Marceau LD: The end of the golden age of doctoring. Int J Health Serv 2002, 32:379-4I6.

5I. Stevenson F, Scambler G: The relationship between medicine and the public: the challenge of concordance. Health (London) 2005, 9:5-2I.

52. Schlesinger $M$ : A loss of faith: the sources of reduced political legitimacy for the American medical profession. Milbank $Q$ 2002, 80: 185-235.

53. Davies $\mathrm{H}$ : Falling public trust in health services: implications for accountability. J Health Serv Res Policy 1999, 4:193-194.

54. Mechanic D: Changing medical organization and the erosion of trust. Milbank $Q$ 1996, 74: I7I-189.

55. Westin M, Ahs A, Brand Persson K, Westerling R: A large proportion of Swedish citizens refrain from seeking medical care-lack of confidence in the medical services a plausible explanation? Health Policy 2004, 68:333-344.

56. Thom DH, Ribisl KM, Stewart AL, Luke DA: Further validation and reliability testing of the Trust in Physician Scale. The Stanford Trust Study Physicians. Med Care I999, 37:5 I0-5I7.

57. Kerse N, Buetow S, Mainous AG, Young G, Coster G, Arroll B: Physician-patient relationship and medication compliance: a primary care investigation. Ann Fam Med 2004, 2:455-46I.

58. Thom DH, Hall MA, Pawlson LG: Measuring patients' trust in physicians when assessing quality of care. Health Aff (Millwood) 2004, 23: I24-I 32.

59. Mainous AG, Baker R, Love MM, Gray DP, Gill JM: Continuity of care and trust in one's physician: evidence from primary care in the United States and the United Kingdom. Fam Med 200 I, 33:22-27.

60. Calnan MW, Sanford E: Public trust in health care: the system or the doctor? Qual Saf Health Care 2004, I3:92-97.

61. Ahern MM, Hendryx MS: Social capital and trust in providers. Soc Sci Med 2003, 57: I I 95-I203.

62. Haas JS, Phillips KA, Baker LC, Sonneborn D, McCulloch CE: Is the prevalence of gatekeeping in a community associated with individual trust in medical care? Med Care 2003, 41 :660-668.

63. Kravitz RL, Hays RD, Sherbourne CD, DiMatteo MR, Rogers WH, Ordway L, Greenfield S: Recall of recommendations and adherence to advice among patients with chronic medical conditions. Arch Intern Med 1993, I53:1869-1878.

64. Garber MC, Nau DP, Erickson SR, Aikens JE, Lawrence JB: The concordance of self-report with other measures of medication adherence: a summary of the literature. Med Care 2004, 42:649-652.

65. Gordillo V, del Amo J, Soriano V, Gonzalez-Lahoz J: Sociodemographic and psychological variables influencing adherence to antiretroviral therapy. Aids 1999, I3:1763-1769.

66. Horne R, Weinman J: Patients' beliefs about prescribed medicines and their role in adherence to treatment in chronic physical illness. J Psychosom Res 1999, 47:555-567.

\section{Pre-publication history}

The pre-publication history for this paper can be accessed here:

http://www.biomedcentral.com/1471-2458/6/52/prepub 